\title{
LA SITUACIÓN JURÍDICA DE LOS EXTRANJEROS EN CANARIAS EN EL ANTIGUO RÉGIMEN
}

\author{
AleXIS D. BRITO GONZÁLEZ \\ Universidad de Las Palmas de Gran Canaria
}

Fecha de recepción: octubre de 2009

Fechas de aprobación: febrero de 2010

La presencia de individuos de otros estados ha constituido una constante en la historia de los reinos hispánicos. Sin necesidad de remontarse más allá de la época medieval, ya en el siglo XIII, la colonia genovesa era tan numerosa e importante en la ciudad de Sevilla que sus miembros obtuvieron una serie de privilegios del monarca Fernando III en 1251. ${ }^{1}$ Esta situación se fue incrementando durante la época bajomedieval de manera que ya en el reinado de los Reyes Católicos se habían promulgado numerosas disposiciones que les atañían directa e indirectamente.

En este período, se produce la incorporación del archipiélago canario a la corona castellana. Las islas habían sido «redescubiertas» en el siglo XIII y ya en el siglo XIV diversas expediciones de procedencia europea (mallorquines, andaluces, portugueses, etc.) propiciaron su conocimiento y entrada en el ámbito europeo. La presencia de los europeos en las islas es, por tanto, una circunstancia que se constata desde muy temprana edad; de hecho, la conquista de las mismas fue iniciada por un grupo de normandos liderados por Jean de Bethencourt y Gadifer de La Salle en 1402. Objeto de disputa entre castellanos y portugueses - los cuales llegaron a controlar durante dos años la isla de Lanzarote -, su conquista no finalizaría hasta 1496 con la ocupación de Tenerife y será, a partir de entonces, cuando se produzca una afluencia más numerosa a las islas de individuos originarios de los países europeos, fundamentalmente genoveses y portugueses en estos momentos iniciales.

La importancia de los extranjeros en España y Canarias durante el Antiguo Régimen ya fue puesta de manifiesto por numerosos autores coetáneos, así como por

1. Todos estos privilegios y mercedes se conservan en El Libro de los privilegios concedidos a los mercaderes genoveses establecidos en Sevilla. Siglos XIII-XVI. Sevilla 1992. 
los recientes historiadores. Esta situación ha generado una significativa, y cada vez más abundante, bibliografía centrada en estas personas, que han sido analizadas e investigadas desde diversos puntos de vista: origen nacional, el social, la dedicación profesional, religioso, etc. ${ }^{2}$ Sin embargo, a pesar del profuso material que sobre ellos se ha publicado, existen numerosas lagunas sobre su situación en la sociedad española; una de ellas es la que hace especial incidencia en su situación jurídica dentro de la monarquía hispánica. Es difícil comprender como el único trabajo que se ocupa de esta cuestión de manera general y amplia es el de Manuel Álvarez Valdés del año $1992^{3}$ aunque existen diversos estudios de carácter más específico, tanto en la cronología como en el ámbito de actuación. ${ }^{4}$ Ello se debe, quizás, a la necesaria integración de dos materias, Historia y Derecho, que complica sobremanera la posibilidad de realizar un estudio en profundidad por parte de una persona especializada en una única área.

Este fenómeno se agrava aún más para el caso del archipiélago canario pues, salvo el caso del libro publicado por M. Pérez Rodríguez, ${ }^{5}$ apenas existen otros de carácter similar. Es, por ello, por lo que presentamos este trabajo de investigación que pretende paliar este déficit al tiempo que analizar la evolución de la situación jurídica de los europeos en Canarias durante el Antiguo Régimen, desde el siglo XVI hasta el XVIII; período de vital importancia para las islas pues pasó de constituir un territorio recién conquistado a otro vertebrado y con unas características definidas. Una etapa de larga duración que nos permite vislumbrar el desarrollo de la legislación así como su adaptación a las diferentes circunstancias que se suceden, su cumplimiento, los conflictos generados.

\section{CONSIDERACIONES GENERALES}

Señalamos al comienzo del artículo que, desde épocas muy tempranas, existieron numerosos grupos de foráneos en los reinos hispánicos. Es por este motivo por lo que, al comenzar la etapa moderna, podemos encontrar una situación jurídica de doble procedencia: por un lado, una legislación nueva que aparece paulatinamente en función de las necesidades y de las nuevas coyunturas con las que se enfrenta la monarquía hispánica; por otro lado, una legislación de herencia bajomedieval, que afecta principalmente a la colonia genovesa, quizás la más antigua, y que se prolongará durante buena parte de esta etapa. Ambas confluirán en los inicios de esta etapa pero, según nos internamos en la misma, la primera quedará como dominadora frente a la segunda.

La llegada de los Austria a la Corona española no supuso un cambio en la legislación castellana. Sí podemos apuntar que se producen transformaciones o nuevas vías

2. Uno de los trabajos generales más relevantes sobre este tema es el publicado por Antonio Domínguez Ortiz: Los extranjeros en la vida española durante el siglo XVII. Madrid 1960.

3. Alvarez-VAldÉs, Manuel: La extranjería en la Historia del Derecho español. Oviedo 1992.

4. Por citar un ejemplo, GonZÁlez Beltrán, Jesús Manuel: «Legislación sobre extranjeros a fines del siglo XVIII». Trocadero No 8-9 (1996-1997) pp. 103-118.

5. Perez Rodriguez, Manuel: Los extranjeros en Canarias. La Laguna 1990. 
motivadas por una serie de condicionantes que generan una nueva situación; como señala J. A. Maravall, la legislación se convierte en emanación de la voluntad soberana propia y todas las normas jurídicas positivas no tienen validez sino en cuanto se apoyan en la voluntad expresa o tácita del soberano. ${ }^{6}$ Esta será una característica de la Monarquía hispánica a lo largo del Antiguo Régimen; el rey dicta las leyes y se cumplen por su voluntad, aunque puede ser asesorado por consejeros.

Una particularidad en lo que concierne a la legislación sobre los extranjeros en España es la carencia de un corpus unitario, es decir, un texto que recoja todas las leyes y órdenes reales que afectan en concreto a estos individuos. Se trata, por tanto, de una legislación dispersa, diseminada si se quiere, pero que evoluciona a lo largo de los tres siglos; que aparece, y desaparece o se transforma, en función de la situación en la que se encuentra la Monarquía y, a menudo, impuesta desde el exterior por la coyuntura política y económica internacional a través de tratados con otras potencias. De ahí, un reglamento que no es tal pues nos encontramos con una progresiva acumulación de leyes, pragmáticas, reales cédulas, etc., que se crean según las necesidades del momento. En buena medida y probablemente por esta causa no cuenta con un carácter definido, a lo cual se debe añadir que ello es debido en parte a que no existe una política clara en lo que respecta a los extranjeros pues, casi siempre y principalmente en los momentos de mayor debilidad, la Corona se debate entre la obligatoriedad y necesidad de contar con estos personajes y la repulsa hacia ellos. Esta dicotomía provoca que, con frecuencia, la ley sea esquivada, eludida, e incluso ignorada, por la propia Corona en función de sus obligaciones, dependencias e intereses. No será, por tanto, hasta principios del siglo XIX cuando podamos hallar una compilación de las normas referentes a los foráneos en la Novísima Recopilación de las Leyes de España, en concreto el Título XI del Libro VI «De los extranjeros domiciliados y transeúntes en estos Reynos»; que, en realidad, no se trata de un conjunto de leyes nuevas sino una reunión de las existentes, muchas de las cuales continuaron en vigencia hasta 1804.

A lo largo del siglo XVI, y dada la posición de fuerza de la Monarquía española, el derecho que afecta a los extranjeros se caracteriza en gran medida por su carácter restrictivo. Así, en 1543, Carlos V prohíbe a los extranjeros tener beneficios y pensiones eclesiásticas en estos Reinos; al mismo tiempo, en 1567 se revocan las cartas de naturaleza para extranjeros y se publican las razones por las cuales las prelacías y dignidades y beneficios del Reino no se hayan de dar a extranjeros, ${ }^{7}$ ley que volverá a ser publicada por Felipe IV en 1632 y Felipe V en 1723. Otras consideraciones, como la prohibición de comerciar con Indias, también reflejan ese carácter restrictivo de los monarcas del Quinientos. Una pragmática de 1552 prohibía a los extranjeros tratar en Indias ya sea él mismo o por persona interpuesta ni tener compañía con alguien que tratase en Indias; tampoco podía comprar oro ni plata ni usar el oficio de corredor de

6. MARAVAlL, José Antonio: Estado moderno y mentalidad social. Madrid 1986, Tomo II pp. 413.

7. Recopilación de las Leyes destos Reynos. Libro I Título III Ley XIV. Esta ley es de clara herencia bajo medieval al ser establecida por Enrique II (1377), Enrique III (1401), Enrique IV (1473) y reiterada igualmente por los Reyes Católicos (1476 y 1480). 
cambios. ${ }^{8}$ La preocupación de los reyes españoles se centraba principalmente en todo lo concerniente con el mundo del comercio, al ser aquel donde la participación de los foráneos era mayor y más evidente. Así, la Ley X del Título XVIII del Libro VI de la Recopilación ordenaba que los mercaderes extranjeros que vinieren a los puertos con mercadurías las vendan y no lleven de retorno oro ni plata ni moneda, ley que en un primer momento únicamente se aplicó a Guipúzcoa, Vizcaya y Navarra pero que se extenderá a todos por los puertos del Reino por la Ley LXIII del mismo título por mandado de Felipe IV en 1632. Junto a ello, se ordenaba que ningún extranjero pudiera ser cambiador en el reino aunque tenga carta de naturaleza, que no pudiesen usar el oficio de corredor de cambios y que los cambios y mercaderes tratantes en estos reinos y fuera de ellos tengan cuenta en castellano en sus libros de caja y manual por debe y ha de haber. ${ }^{9}$

Uno de los puntos más interesantes y discutidos es el tema acerca de la naturaleza y vecindad, debate que se prolongó durante toda la etapa moderna entre los juristas coetáneos. No vamos a entrar en demasiada profundidad pues ya ha sido analizado por diversos autores, ${ }^{10}$ aunque sí reseñar algunos aspectos sobre esta cuestión. Tanto la naturalización como la adquisición de la vecindad son dos caras de una misma moneda: el asentamiento de los extranjeros y su integración social. La consideración de vecinos tenía múltiples ventajas entre las cuales podemos destacar el disfrute de ciertos derechos, que conllevaban igualmente el cumplimiento de algunos deberes como vecino. La adquisición de la vecindad continúa siendo controvertida pues algunos autores señalan que era necesario un pronunciamiento de las autoridades mientras que otros destacan que no respondían a criterios claros y estaba vinculada a la reputación. Lo que sí queda claro es que debe haber un evidente deseo por parte del extranjero de formar parte de la comunidad. A diferencia de la vecindad, la naturalización generó una abundante legislación en la edad moderna. Una Real Cédula de Felipe II en 14 de julio de 1561 dictaminaba que aquellos extranjeros domiciliados en los territorios españoles durante diez años con casa y bienes de asiento y casados con mujeres naturales de dichos reinos que viviesen en su compañía podían solicitar y obtener la ansiada carta de naturaleza. ${ }^{11}$ Estas condiciones se endurecieron a principios del siglo XVII pues Felipe III, por una Real Cédula de 1608, aumentaba el período de residencia hasta los veinte años, diez de ellos continuados, y además el Consejo de Indias debía presentar un dictamen tras ver la información y diligencias presentadas, las cuales debían realizar antes las audiencias, gobernadores o justicias superiores. No obstante, como señala T. Herzog, personas a las que faltaban requisitos podían adquirir la naturalización al

8. Reiterada en la Recopilación de las Leyes... Libro VI Título XVIII Ley V.

9. Recopilación de las Leyes... Libro V Título XVIII («De los cambios y cambiadores y corredores dellos y de los mercaderes y interesses») Leyes VI, VII y X.

10. HeRzoG, Tamar: Vecinos y extranjeros. Hacerse español en la Edad Moderna. Madrid, 2006.

11. (A)rchivo (G)eneral de (I)ndias Sección Indiferente Leg. 428 fol. 187 rto-190vto. 
tiempo que a otras se les negaba dicho status a pesar de cumplirlos si su lealtad era cuestionada. $^{12}$

Ahora bien, el uso de las cartas de naturaleza provocó conflictos entre los monarcas y el reino, debido a que éste consideraba que aquel abusaba de su autoridad concediendo la naturalización a gente indigna de ellas. Para evitarlo, desde el siglo XVII comenzaron a distinguirse aquellas cartas de naturaleza concedidas por el monarca a través de la Cámara de Castilla para los que cumplían los requisitos de integración y las cartas de naturaleza concedidas para determinados aspectos, como el comercio con Indias, que no suponían una verdadera naturalización y limitaban su efecto a la razón por la que eran expedidas. ${ }^{13}$

La consecuencia de todo ello se produjo ya en el siglo XVIII con la Instrucción de 1716, por la cual se reconocía a los extranjeros transeúntes, que disfrutarían del fuero de extranjería y serían considerados como extranjeros, y los extranjeros avecindados y arraigados, que se equipararían a los naturales en privilegios y obligaciones considerándolos vasallos de la Corona. Situación que quedaría confirmada posteriormente en las órdenes emitidas bajo Carlos III para la elaboración de las matrículas a mediados de ese mismo siglo.

La progresiva debilidad de la Monarquía hispánica durante el siglo XVII, tanto en los asuntos políticos como económicos, se traduce en una serie de concesiones a las distintas potencias europeas en lo que concierne a la estancia y/o asentamiento de los súbditos de aquellas en los territorios hispánicos, entre ellas la posibilidad de contar con representantes de dichas naciones, individuos que les protejan ante problemas legales y defiendan sus intereses, etc. Así, por ejemplo, en 1645 los ingleses obtenían de Felipe IV la concesión de tener un juez conservador en Sevilla, Málaga, Cádiz y Sanlúcar de Barrameda

«[...] el cual haya de apremiar y compeler a todas y cualesquier personas, de cualquier suerte y calidad que sean que tocaren a la dicha nación, así en aquella en fueren reos convenidos, como en las que fueren actores, aunque las personas que los convinieren y que de ellos fueren convenidos tengan cualesquier jueces privativos, asi por asiento o por contrato que hayan hecho, como por preeminencias o inmunidades que tengan, porque de las dichas causas solo ha de conocer privativamente el dicho juez conservador, y no otro juez ni tribunal alguno, aunque sea por via de esceso, ni de injusticia notoria o en otra cualquier manera o forma $[\ldots]\rangle^{14}$

12. HerzoG, Tamar: op. cit. pp. 118.

13. Ibidem pp. 126.

14. CAntillo, Alejandro del: Tratados, convenios y declaraciones de paz y de comercio que han hecho con las potencias extranjeras los monarcas españoles de la Casa de Borbón desde el año de 1700 hasta el dia. Madrid 1843, pp. 137-140. Esta Real Cédula fue reiterada y complementada por otra de 26 de Junio de 1645 pero, ante la oposición de la Audiencia de Sevilla, Felipe IV promulga una tercera de 9 de Noviembre de 1645 en la que limita las capacidades y poderes del juez conservador a «... cuando los pleitos fueren entre los de vuestra nacion, ora seais actores ora reos, y las causas fueren civiles o criminales [...] y cuando los dichos pleitos fueren con españoles o con otras personas de diferentes 
Muchas de estas concesiones se obtenían a través de los distintos tratados que la Corona española firma con los estados europeos. Se puede señalar el tratado firmado con Inglaterra en 1604 como el primero que va a inaugurar una nueva etapa en las relaciones con el resto de los países. Por él se establecía la libertad de comercio entre ambas naciones y se permitía a los protestantes ingleses comerciar en España sin ser molestados, siempre y cuando no diesen motivos de escándalo. Poco antes, los naturales de Hamburgo y otras ciudades marítimas de Alemania habían conseguido unas garantías similares en $1597 ;^{15}$ en 1607 , un tratado con las ciudades hanseáticas les concedía una serie de privilegios para desarrollar sus actividades comerciales en Andalucía, entre ellas la de un juez conservador. Similares tratados en los que se otorgaba cierta tolerancia en materia religiosa se firmaron con Dinamarca en $1641 \mathrm{y}$ Holanda en 1648.

Sin embargo, todas estas concesiones y privilegios no deben hacernos olvidar que, cuando se producían los conflictos bélicos, la mayoría de las mismas quedaban suspendidas. Es más, en estos períodos de enfrentamientos, la Corona va a actuar duramente contra los naturales procedentes del Estado con el que se lucha. Una de las medidas más empleadas consistía en el embargo de sus bienes; así sucedió en 1635 cuando Francia entró en guerra con España, ${ }^{16}$ en 1656 en el conflicto con Inglaterra ${ }^{17}$ y nuevamente con los franceses en $1667 .{ }^{18}$ Se trataba de obstaculizar los intereses del país enemigo mediante bloqueos y expulsiones, a la vez que la obtención de una serie de ingresos a través de los embargos con los que costear, en parte, el conflicto. No obstante, la efectividad de dichas medidas fue siempre cuestionable ya que la misma Corona concedía licencias de importación así como la posibilidad de anular las confiscaciones con el pago de un donativo o servicio por parte de los particulares, por no mencionar ya del fraude y contrabando ejercido por dicha nación u otras, con o sin el consentimiento de las autoridades locales. ${ }^{19}$

naciones, el juez conservador haya de conocer y conozca solamente de las causas en que fueredes civil o criminalmente reos convenidos ...».

15. Carta acordada de 17 de Mayo de 1597. (A)rchivo del (M)useo Canario Sección Inquisición XIX-13 fol. 66 rto-69 rto.

16. La Real Cédula de 3 de Junio de 1635 ordenaba el embargo de bienes de los franceses. (A)rchivo (H)istórico (P)rovincial de (L)as (P)almas Sección Audiencia Libro 35 (Libro de Títulos) fol. 149 vto- 150 rto.

17. Por Real Cédula de 30 de Marzo de 1656 se ordena a los ingleses salir de los puertos; asimismo se crea una junta para la cobranza y administración de los bienes de la represalia de los ingleses. A.H.P.L.P. Sección Audiencia Libro 35 fol. 279 vto para el primero y fol. 281 rto para el segundo.

18. Muchas de las decisiones tomadas en este conflicto tienen como base las desarrolladas en 1635. SANCHEZ Belen, Juan Antonio y Ramos MedinA, Ma Dolores: «La Junta de Represalias de 1667 y el comercio de géneros de Francia». En El comercio en el Antiguo Régimen, III Reunión Científica de la Asociación Española de Historia Moderna (1994), Las Palmas de GC 1995, Vol. II pp. 245-260.

19. Un hecho que lo demuestra sucedió a finales del siglo XVI en Canarias. En 1593 en una rutinaria visita de navío los inquisidores descubrieron una red de comerciantes y capitanes de navíos que importaban productos desde las provincias rebeldes de Holanda cuando el comercio con esa zona se hallaba prohibido desde mucho tiempo atrás. Fueron detenidas las tripulaciones de tres navíos y los inquisido- 
La llegada de los Borbones al trono español supuso una serie de cambios con la introducción de nuevas ideas sobre el Estado y la forma de gobernar. En lo que concierne a los extranjeros se aprecia un incremento de la legislación acerca de estos individuos destinada, por un lado, a conseguir un mayor control sobre un colectivo que había crecido de forma notoria a lo largo del siglo XVII, atraído por el comercio y la posibilidad de adquirir parte de la plata americana, $y$, por otro lado, en un intento de coartar los logros y concesiones obtenidas sin llegar al incumplimiento de los tratados $\mathrm{y}$ acuerdos vigentes con otras potencias europeas.

Un ejemplo de la necesidad de un control y de un organismo que supervisase la legislación en torno a este grupo lo constituye la creación de una Junta para los negocios pendientes que tocaban a la nación francesa en $1714 .{ }^{20}$ Suprimida en 1717 , fue restablecida en 1721 bajo el nombre de Junta de Dependencias y Negocios de Extranjeros ${ }^{21}$ para, finalmente, ser agregada en 1748 a la Junta de Comercio y Moneda. ${ }^{22}$ Dependiente durante bastante tiempo del Consejo de Estado, dicha Junta se encargaba de todos los asuntos relacionados con los extranjeros, bien en la elaboración de informes o memoriales que elevaba al rey o bien decidiendo y asesorando al monarca en cuestiones que éste les planteaba. Asimismo, se ocupaba de todo aquello vinculado a los cónsules y vicecónsules, sus competencias, rechazar o aceptar las Patentes expedidas, dirimir en los conflictos, etc.

Entre los objetivos para limitar las concesiones producidas en el siglo XVII se encontraban los jueces conservadores. El Consejo de Estado resolvió en 1715, de acuerdo con el parecer de la Junta de Dependencias de Extranjeros, que «[...] siempre que pidan las Potencias Extranjeras que hubieren capitulado se les nombrase jueces conservadores debia concederseles pero solo en aquellas partes que los tuvieron en el

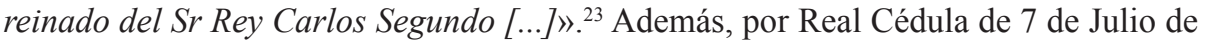
1727, los jueces conservadores

res sospechaban que las autoridades civiles estaban al tanto de todo aunque no pudieron actuar contra ellos. Thomas, Werner: «Contrabandistas flamencos en Canarias: 1593-1597». IX Coloquio de Historia Canario-Americana (1990) Las Palmas de GC 1992, Tomo II pp. 55-92.

20. Real Decreto de 12 de Marzo de 1714. (A)rchivo (H)istórico (N)acional Sección Estado Leg. 647 exped. 1.

21. El Real Decreto de 3 de Noviembre de 1721 señalaba que «teniendo presente lo útil y provechoso que fue a la expedición de los negocios extrangeros la Junta que para la más segura dirección de ello se formó el año pasado de 1714 y se intituló de Dependencias y negocios de Extrangeros compuesta de Ministros de los Consejos de Estado, Guerra, Castilla, Indias y Hacienda, hasta que con motivo de la última guerra quedó extinguida. Y considerando que la Paz general que se va a establecer augmentará los mismos negocios extrangeros que deseo tratarlos con la mayor justificación y puntualidad en su expedición por lo que importa mantener y augmentar más y más la buena correspondencia con los soveranos y Payses extrangeros, he resuelto restablecer y formar de nuevo la referida Junta [...] y que sea compuesta de un Consegero de Estado que la presida, de dos Ministros de cada uno de los principales tribunales de la Corte y de un secretario y tres oficiales [...]». A.H.N. Sección Estado Leg. 647 exped. 3.

22. Real Orden de 21 de Diciembre de 1748. A.H.N. Sección Estado Leg. 647 exped. 14.

23. Minuta del Consejo de Estado de la consulta que hizo en 2 de marzo de 1715 relativa a los nombramientos de jueces conservadores. A.H.N. Sección Estado Leg. 609 (Caja 2) exped. 45. 
«[...] unicamente habeis de conocer y conozcais de los litigios que hubiere y resultaren entre sugetos de la propia Nación (de tal parte), siendo comerciantes transeúntes, que habitan, van y vienen a estos Reynos a comerciar por mayor, y no de los avecindados y arraygados en España; porque el privilegio que concedo a aquellos no ha de trascender a estos por ningún motivo, causa o razón que se ofrezcan, respecto de que las dependencias y litigios de los que están avecindados y arraygados en mis dominios tienen otra naturaleza, y deben seguir precisamente las mismas reglas que mis vasallos y súbditos sin diferencia alguna $[\ldots]\rangle^{24}$

Es decir, a partir de ahora, dependiendo de la situación de cada extranjero se acogerá a un fuero u otro, el de extranjería o las leyes del reino; y en este sentido, los jueces conservadores sólo podrán actuar en aquellos casos de foráneos transeúntes. Además por esta misma cédula, se fijaba que las apelaciones debían ser llevadas al Consejo de Guerra de Justicia donde se determinaba sin posibilidad de recurso a instancias superiores. Esta situación ya se recogía en el artículo 15 del Tratado de Utrecht con Gran Bretaña: «[...] Consiente el rey católico que las apelaciones de las sentencias dadas en causas pertenecientes a los súbditos ingleses se lleven al tribunal del consejo de guerra de Madrid y no a otra parte.»

A pesar de lo dicho y sin entrar en aparente contradicción, parece que la institución de los jueces conservadores va a ir desapareciendo paulatinamente, según Recondo en un período de tres décadas, en el cual las causas de los transeúntes eran conocidas según la nación implicada, bien por la jurisdicción militar bien por los jueces conservadores. ${ }^{25}$

Estas pretensiones de examinar e inspeccionar la asistencia de los europeos permanecerán casi inalteradas hasta comienzos del siglo XIX. Otra muestra del control que la nueva dinastía intentó ejercer sobre los extranjeros residentes en los territorios hispánicos consistió en la elaboración de listas o matrículas en las que se hiciesen constar una serie de datos relativos a estas personas. Con anterioridad, se habían realizado algunas de manera puntual ${ }^{26}$ pero no será hasta Carlos III cuando se intente llevar a de manera efectiva ordenando por real cédula

«[...] que anualmente se forme en todos los Puertos y lugares de comercio una lista de los comerciantes y demas personas extrangeras que haya en ellos con separacion de las

24. Recogida en la Ley V Título XI Libro VI de la Novísima Recopilación.

25. Aunque se puede colegir que ya había desaparecido a finales del siglo XVIII. Citado en ALVAREZVALDES, Manuel: op. cit. pp. 412.

26. Un ejemplo de la utilización de listas, censos y matrículas ocasionales para conocer la comunidad extranjera en un determinado lugar podemos encontrarlo en los siguientes trabajos. FAJARDO SPINOLA, Francisco: «Portugueses en Canarias en el siglo XVII. Una relación de 1626». XV Coloquio de Historia Canario-Americana (2002), Las Palmas de GC 2004, pp. 310-320; OZANAM, Didier: «La colonie francaise de Cádiz au XVIIIe siècle, d'après un document inédit (1777)». Melanges de la Casa de Velázquez, Tomo IV (1968), pp. 259-347; PONSOT, Pierre: «Des inmigrants français en Andalousie: exemples de Montilla (1689-96) y et d'Osuna (1791)». Melanges de la Casa de Velázquez, Tomo V (1969), pp. 331341; RoldAN GuAL, Jose María: «Inmigrantes franceses en Fuenterrabía: un censo de 1611». Lurralde no 10 (1987), pp. 129-144. 
Naciones firmando todos sus nombres con expresion de si son transeuntes o domiciliados reputados por vasallos mios renovandola cada año con los que vinieren de las respectivas Naciones o entraren a ser Nacionales españoles [...] remitiendo todos los años copia de ella $[\ldots]\rangle^{27}$

Intento que en la mayoría de los casos no tuvo una continuidad apreciable, salvo en algún territorio concreto como Navarra, ${ }^{28}$ y que es uno de los puntos manifestados en las órdenes de Carlos IV para que se retome su confección tras los sucesos acaecidos en Francia con la Revolución Francesa.

Por tanto, durante la etapa moderna podemos distinguir una evolución en la legislación que atañe a los extranjeros que residen en los reinos españoles; evolución que se traduce en un notable aumento de las normas que les afectan, emanadas tanto de los monarcas como de los organismos e instituciones que les asesoran, es decir, nos encontramos con la paulatina aparición de un reglamento o código de leyes destinado exclusivamente hacia este colectivo. Si en el siglo XVI se trataba de leyes dispersas, a menudo imprecisas y situadas dentro del ámbito preventivo y restrictivo, a finales del siglo XVIII las hallamos reunidas y totalmente definidas en un bloque compacto y coherente, mucho más realista y acorde con la situación imperante en ese período.

\section{SITUACION JURIDICA DE LOS EXTRANJEROS EN CANARIAS}

Estamos de acuerdo con el profesor J. Lalinde Abadía en que, desde el punto de vista del Derecho, Canarias no constituye un área especial sino que forma parte del área meridional castellana y, por lo tanto, no existe un ordenamiento jurídico diferente. ${ }^{29}$ En este sentido, todo lo desarrollado en el apartado anterior sobre la situación jurídica de los extranjeros en España es aplicable igualmente a Canarias. No obstante, debido a ciertos condicionantes, tanto históricos como geográficos e incluso económicos, a las órdenes y leyes citadas se añaden otras de carácter específico para el archipiélago canario que, sin alterar de manera radical y significativa el status jurídico de los foráneos, suponen algunas modificaciones o variaciones y dan lugar a una especial idiosincracia.

Al margen de los normandos que iniciaron la conquista de las islas a comienzos del siglo XV, la llegada de los europeos a las islas se va a producir tras la finalización de la conquista de las llamadas «islas de realengo»: Gran Canaria (incorporada a Castilla en 1483), La Palma (en 1494) y Tenerife (en 1496). A ellas se van a desplazar inicialmente un nutrido grupo de genoveses y portugueses; los primeros, debido a su participación en la conquista como financiadores obtendrán datas de tierras y aguas en los repartimientos y se interesarán por el negocio del azúcar de manera que, en una

27. Real Cédula de 28 de Junio de 1764. A.H.N. Sección Estado Leg. 629 (Caja 1) exped. 2.

28. SAlas Ausens, José Antonio y JARQue MARTineZ, Encarna: «Extranjeros en España en la segunda mitad del siglo XVIII». Actas del Coloquio Internacional «Carlos III y su siglo» (1988), Madrid 1990, Tomo II pp. 985-997.

29. Lalinde AbadiA, Jesús: «El Derecho castellano en Canarias». Anuario de Estudios Atlánticos $\mathrm{N}^{\circ} 16$ (1970) pp. 13-35. 
fecha tan temprana como 1488, se confirma la venta a Batista de Riberol, genovés, de unas casas y heredades para construir un ingenio de azúcar. ${ }^{30}$ El acaparamiento de tierras y propiedades es tal que, en 1499, los Reyes Católicos se ven obligados a dar una Orden al gobernador de Gran Canaria para que impida que los genoveses compren heredades en cuantía superior a doscientos mil maravedies aunque tengan concedida carta de naturaleza en dicha isla y que aquellos que las tuviesen las vendiesen antes de un año o las perderían. ${ }^{31}$ Sin embargo, la presión de los genoveses en la Corte consigue que esa orden únicamente se ejecute en los bienes comprados después del pregón de 14 de Junio de 1498. Si bien inicialmente esta medida afectó a los genoveses, parece que pronto se hizo extensiva a los extranjeros en general por lo que se deduce de la carta de naturaleza concedida a Lorenzo Fernández, portugués, para poseer bienes por valor superior a doscientos mil maravedíes. Por otro lado, la misma Corona va a propiciar su incumplimiento al conceder licencias y confirmaciones que benefician a varios de estos individuos, sentando así un peligroso precedente ya que, con el tiempo, esta norma va a quedar en letra muerta. ${ }^{32}$

Una de las razones principales que motivaron la llegada y asentamiento de los extranjeros en Canarias fue la posibilidad, cada vez más significativa, de poder comerciar con Indias. Al parecer, no será hasta 1526 en que las relaciones comerciales con el continente americano se inicien de manera oficial cuando Carlos I autoriza a los isleños, durante un período de dos años, a llevar a América mantenimiento, provisiones y

30. Confirmación dada en Valladolid el 20 de Noviembre de 1488. AZNAR VALLEJO, Eduardo: Documentos canarios en el Registro del Sello (1476-1517). La Laguna 1981.

31. Orden de 31 de Octubre de 1499. Ibidem.

32. Algunos ejemplos de estas excepciones son:

1502-Febrero-2. Sevilla. Carta de naturaleza a Lorenzo Fernández, de Portugal, para que pueda poseer en Gran Canaria cuantas propiedades quisiere, librándose de las penas que pesen sobre él por incumplir la prohibición de que los extranjeros no posean propiedades por valor superior a doscientos mil maravedíes, en recompensa de haber sido uno de los primeros en hacer azúcar en la isla, en la que ha residido durante quince años y haber enseñado a muchos vecinos a hacerlo.

1506-Febrero-26. Salamanca. Licencia al tesorero Alonso Gutierrez de Madrid para que pueda vender el ingenio y heredamiento que posee en Agaete, en Gran Canaria, al genovés Antonio de Cerezo, a pesar de la prohibición de que los extranjeros adquieran bienes valorados en más de doscientos mil maravedíes. Dicho heredamiento fue de Francisco Palomar, hermano de Antonio de Cerezo, que fue desposeído por haber cometido cierto delito.

1512-Julio-16. Burgos. Licencia a Francisco de Riberol, estante en Gran Canaria, para que pueda comprar las posesiones que el doctor Galíndez de Carvajal, del Consejo Real, tiene en dicha isla, no obstante, la pragmática que prohibe a los genoveses y extranjeros tener haciendas superiores a doscientos mil maravedíes.

1513-Mayo-4. Valladolid. Confirmación a Francisco de Riberol y a su hermano Cosme de Riberol de la vecindad que les fue concedida por el Concejo de Gran Canaria, haciéndola extensiva a Agustín de Riberol, hijo de Cosme, y a Pedro Juan de Riberol, sobrino de ambos. Se les confirma asimismo, las propiedades que poseen en dicha isla aunque sobrepasen los doscientos mil maravedíes de valor, dado que se han concertado con el secretario Lope de Conchillos, a quien se hizo merced de las penas en que incurriesen los extranjeros por poseer bienes superiores a dicha cantidad.

Todo ello en AZNAR VALLEJO, Eduardo: op. cit. 
demás bienes producidos en el archipiélago. ${ }^{33}$ Desde entonces, y salvo momentos muy concretos, el permiso fue renovándose por períodos de dos, tres o cuatro años. Una Real Cédula de 8 de Septiembre de 1546 encargaba a las autoridades insulares que no permitiesen a Indias el paso de extranjeros; ${ }^{34}$ poco después, por una real provisión de Felipe II, con fecha de 8 de Agosto de 1558, se vuelve a reiterar que ninguna persona que no estuviese avecindado pudiese cargar y comerciar con Indias desde las islas. ${ }^{35}$ Por fin, una Real Cédula de 14 de Julio de 1561 equiparaba a los naturales de los reinos de España a los extranjeros domiciliados en los territorios españoles durante diez años con casa y bienes de asiento, con tal que estuviesen casados con mujeres naturales de dichos reinos y que viviesen en su compañía. ${ }^{36}$ Como ya hemos mencionado, estas condiciones permanecerán en vigencia hasta que Felipe III promulgase la cédula de 1608 ampliando el período a veinte años, diez de ellos casados. A pesar de estas condiciones, la Corona reiterará continuamente que no pasen a Indias navíos extranjeros, lo cual no es sino una muestra del incumplimiento de las mismas. ${ }^{37}$

Junto a estas disposiciones sobre el comercio americano, podemos encontrar algunas relacionadas con el comercio europeo. Como consecuencia de los conflictos internacionales, Felipe II envía en 1596 una cédula a la Real Audiencia de Canarias sobre que no se puedan vender mercadurías de Inglaterra así como traficar con Holanda, ${ }^{38}$ lo cual constituye un ejemplo significativo de que estas acciones se continuaban produciendo pese a las prohibiciones y los conflictos bélicos. En este caso, la cédula pudo ser una consecuencia del descubrimiento en 1593 de una red de contrabando en las islas de navíos holandeses que llegaban con pasaportes falsos y que supuso la detención de varios navíos y sus tripulaciones por el Santo Oficio. ${ }^{39}$

33. Real Cédula de 4 de Agosto de 1526. Rumeu De Armas, Antonio: Canarias y el Atlántico. Piraterías y ataques navales. Madrid, 1991, Tomo I pp. 291-292.

34. Ibidem pp. 293.

35. PeraZA De Ayala, José: El régimen comercial de Canarias con las Indias en los siglos XVI, XVII y XVIII. La Laguna, 1952 pp. 21

36. Ibidem pp. 22. También en A.G.I. Sección Indiferente Leg. 428 libro 2 fol. 187 rto.-190 vto.

37. Por ejemplo:

1573-Noviembre-10. Cédulas al juez oficial de Gran Canaria, Tenerife y La Palma. Para que ningún extranjero vaya por piloto a Indias ni por oficiales, al tener noticias de que en las naos que van a Indias pasan ingleses y franceses.

1603-Mayo-9. Cédula a los jueces oficiales de Canaria. Para que no den licencia para navegar a Indias a ningún navío extranjero.

1604-Abril-2. Cédulas a los jueces de registro de Canaria, Tenerife y La Palma. Para que no den despacho para que ningún navío extranjero vaya a Indias ni extranjeros aunque vayan en navíos de naturales, salvo expresa dispensación del monarca.

En Morales Padrón, Francisco: Cedulario de Canarias. Las Palmas de GC 1970, 3 vols.

38. Real Cédula de 21 de Enero de 1596. A.H.P.L.P., Sección Audiencia Libro I (Reales Cédulas y órdenes particulares para Canarias) fol. 199-200.

39. La mayor parte de estos holandeses desfilarían en el auto de fe que se celebró en Las Palmas en 1597. Muchos de ellos aún permanecían en las cárceles inquisitoriales cuando en 1599 se produjo el ataque de 
A un nivel más local surgen normas dictadas por los Concejos de las islas, fundamentalmente centradas en torno al comercio. En este sentido, quizás los más activos fueron los de Tenerife y La Palma; por ejemplo, por acuerdo de 9 de octubre de 1523 , el Cabildo de Tenerife

«acordó que ciertas ropas y mercaderías que quieran sacar los mercaderes flamencos, que no se saquen, pues hay Ordenanza en la tierra; sino que están para provisión de la isla y por haber vendido la peor y llevado muchas sumas de $\mathrm{m}$ [a]r[avedíe]s con poca mercadería $\rangle^{40}$

Una de las principales preocupaciones que surgen durante el reinado de Felipe II se centra en la entrada de herejías protestantes en los territorios hispánicos. Según la definición dada por la Recopilación, hereje es aquel cristiano bautizado que no cree en los artículos de la fe católica por lo que sus bienes pueden ser embargados para la Cámara. ${ }^{41}$ Para impedir la posible entrada de publicaciones e imágenes contrarias a la fe católica se instaura, desde mediados del siglo XVI, el sistema de las visitas de navío. En 1579, mediante un acuerdo entre el Consejo Real y la Inquisición, se establece una reglamentación por la cual se concede al Santo Oficio la prerrogativa de ser la primera institución que visitase las embarcaciones que llegasen a puerto en busca de objetos prohibidos. ${ }^{42}$ Esta medida va a ser una constante fuente de problemas hasta bien entrado el siglo XVIII pues era considerada por los extranjeros como un perjuicio para el comercio, por los derechos que cobraban indebidamente los inquisidores y, en general, porque coartaba la libertad de comercio que buscaban los europeos. Pero además se convierte en un quebradero de cabeza para las instituciones centrales por los conflictos entre las distintas instituciones insulares que pretendían ser la primera en abordar los navíos y percibir los derechos de las visitas, aún cuando, teóricamente, ese status correspondía a la Inquisición. En 1636, varios comerciantes ingleses afincados en Tenerife presentaron un escrito ante la Suprema quejándose de las triquiñuelas que realizaban los comisarios encargados de las visitas de navío para cobrar más derechos; el Consejo escribió al tribunal canario, el cual ordenaba al comisario de La Laguna que averiguase lo que estaba sucediendo. ${ }^{43}$ A pesar de las advertencias, la situación persistió pues en 1675 la Suprema remitía al tribunal insular una copia de un memorial

van der Does, siendo liberados por éste. THOMAS, Werner: «Contrabandistas flamencos en Canarias...», art. cit.

40. Acuerdos del Cabildo de Tenerife. IV: 1518-1525. Edición y estudio de Elías Serra Rafols y Leopoldo de la Rosa, San Cristóbal de La Laguna, 1970 pp. 222-223.

41. Recopilación... Libro VIII Título III («De los herejes y reconciliados, adivinos, hechiceros y agoreros) Ley I.

42. Contreras, Jaime: El Santo Oficio de la Inquisición de Galicia. 1560-1700. Madrid, 1982 pp. 151-157.

43. Se realizaron indagaciones con testificaciones de vecinos que confirmaron los excesos y abusos de los comisarios del tribunal en los puertos de Tenerife. BRITO GONZALEZ, Alexis D.: «Visitas de navío en el tribunal inquisitorial canario: conflictos jurisdiccionales y percepción de derechos». XVI Coloquio de Historia Canario-Americana (2004), Las Palmas de GC 2006, pp. 2053-2062. Sobre este tema, véase también FAJARDO SPINOLA, Francisco: «La vigilancia del mar. La Inquisición canaria y las visitas de navío». Anuario de Estudios Atlánticos nº 49 (2003), pp. 87-124. 
presentado por el cónsul inglés y varios mercaderes sobre la misma cuestión. La resistencia de algún mercader en no pagar los derechos de la visita frente a los abusos se encontraba inexorablemente con la prisión hasta saldar el pago.

Esta no va a constituir la única actividad del Santo Oficio relacionada con los extranjeros. El tribunal inquisitorial canario será especialmente beligerante para obtener la conversión (o reducción, según el término empleado en la época) de protestantes al catolicismo, fenómeno que contaría con su máximo apogeo entre 1671 y $1760 .{ }^{44}$ Muchas de estas conversiones no siempre resultaban pacíficas y provocaban continuos conflictos, tanto entre los inquisidores y los foráneos como entre aquellos y las instituciones locales que, con frecuencia, se aliaban a los europeos por contar con intereses comunes. En 1654 los inquisidores escribieron al Consejo quejándose de que algunos protestantes ingleses y holandeses impedían la reducción de protestantes enfermos y solicitaban licencia para actuar, a lo que la Suprema declara que

«... han sido de parecer q puede y debe el $\mathrm{S}^{\text {to }}$ oficio exercer su jurisdicion contra aquellos Hereges que prohiben y (roto) a un catholico al entrar a visitar al enfermo herege y si este ha hecho alguna demostracion de quererse reducir a nra santa y verdadera Fe Catholica pero que si no la huviere hecho no tendra jurisdicion el santo oficio porque se opone a los capitulos de las pazes con que entran en estos Reynos, suponiendo estar libres en su estado [...] advirtiendo $\mathrm{q}$ en estos casos aveis de entrar con mucha prudencia y con plena información por donde conste q los hereges enfermos han dado muestras de quererse convertir $[\ldots]\rangle^{45}$

En la respuesta de la Suprema se advierte la doble tesitura ante la que se encuentra el tribunal: de una parte, su lucha contra la herejía y conseguir la ansiada conversión de todos aquellos que así lo deseasen, ya fuese de una manera más o menos voluntaria; de otra parte, veía sus atribuciones cada vez más coartadas por la presión de la Corona, la cual se hallaba obligada ante los compromisos contraídos con los distintos estados europeos. De ahí que lo que siempre se aconseja es la prudencia y la información antes de actuar, evitando así que estos individuos puedan quejarse ante sus respectivos representantes sobre el mal trato que se les daba en las islas. La consecuencia de esta política es que, con frecuencia, se producía una cierta inacción del tribunal canario a la espera del dictamen desde Madrid, por lo que muchos asuntos se solucionaban de motu propio.

Apuntamos que el tratado de 1604 entre Inglaterra y España va a significar una nueva etapa en las relaciones con los países no católicos pues, además de establecer la liberta de comercio entre ambas naciones, permitía a los protestantes ingleses comerciar en España sin ser molestados siempre y cuando no diesen motivos de escándalo; otros obtuvieron privilegios similares, como las ciudades hanseáticas en 1607 o los

\footnotetext{
44. FAJARdo SPINOLA, Francisco: «Un producto de las relaciones atlánticas: la conversión de protestantes en Canarias durante el siglo XVIII». X Coloquio de Historia Canario-Americana (1992), Las Palmas de GC 1994, Tomo II pp. 436-458; y Las conversiones de protestantes... pp. 23-41.
}

45. Respuesta dada en 25 de junio de 1666. A.M.C. Sección Inquisición VIII-5 fol. 172 rto. 
holandeses durante la Tregua de los Doce Años. ${ }^{46}$ Sin embargo, el Santo Oficio no permaneció impasible ante estos hechos y consiguió que únicamente afectasen a los que se hallaban de paso y no a los asentados. ${ }^{47}$ Aún con esta situación, el número de extranjeros protestantes que arribaban a las islas se fue incrementando, y un hecho que demuestra la aceptación de las reglas así como la aquiescencia de los canarios respecto a ellos es la escasa conflictividad que encontramos en este período. Esta surgía fundamentalmente tras el rompimiento del estado de paz entre España y otro país, como sucedió con Inglaterra en 1626 o con Francia a partir de 1635. De hecho, en 1654 el tribunal canario volvió a escribir a la Suprema alarmado por el alto número de ingleses y holandeses que se hallaban en la isla de Tenerife, y que cifraban en unos 1.500 individuos, un dato posiblemente exagerado pero que demuestra cómo este colectivo permanecía en las islas sin causar más alarma que a las instituciones eclesiásticas.

A diferencia de algunas zonas de la Península, ${ }^{48}$ en Canarias no se crearon instrumentos donde se registrasen los avecindamientos de forasteros en las ciudades insulares. Las autoridades locales no sintieron la necesidad de crear un medio que atestiguase la voluntad de asentarse por los extranjeros; por eso dicha voluntad debemos localizarla a través de otras manifestaciones documentales. Algunas de dichas expresiones pueden consistir en la aparición en las escrituras notariales con la condición de vecinos, la adquisición de bienes raíces (tanto urbanos como rurales), la participación en las instituciones locales civiles y eclesiásticas, etc. Ninguno de ellos supone un cambio crucial en la situación legal de los individuos que decidiesen asentarse de manera definitiva; sin embargo, es verdad que determinadas actitudes, como la compra de bienes inmuebles o la implicación en ciertas instituciones como las milicias locales, el ayuntamiento o regimiento, etc., facilitaba su consideración como vecino. Por ello, no es de extrañar que quien más o quien menos dirigiese buena parte de sus esfuerzos económicos a la

46. «Que se guarden con los Holandeses los capitulos de paces que con los ingleses, 18 de febrero de 1612». Citado por FAJARDo SPINOLA, Francisco: Las conversiones de protestantes... op. cit. pp. 16.

47. Carta acordada de 18 de Mayo de 1610, reiterada en 18 de Febrero de 1612 y 19 de Mayo de 1620. A.M.C. Inquisición XIX-13 fol. 66 rto.-69 rto.

48. Por ejemplo, en Valencia los libros de avecindamiento han permitido a la profesora Emilia Salvador Esteban analizar la presencia de extranjeros en dicha ciudad en los siglos XVI y XVII. En «Presencia italiana en la Valencia del siglo XVI. El fenómeno del avecindamiento». Saitabi n 36 (1986), pp. 167186; y «Mercaderes extranjeros en la Valencia de los siglos XVI y XVII. Entre la atracción y el rechazo». En La burguesía española en la Edad Moderna (1991), Valladolid 1991, Tomo III pp. 1137-1155. Algo similar sucedía en Bilbao donde cualquier foráneo debía presentar una información de limpieza genealógica para poder ser vecino de la ciudad. GARAY BELATEGUI, Jon y LóPEZ PÉREZ, Rubén Esteban: «Los extranjeros en el señorío de Vizcaya y en la villa de Bilbao a finales del Antiguo Régimen: entre la aceptación y el rechazo». Estudios Humanísticos. Historia $n^{\circ} 5$ (2006), pp. 185-210. 
obtención de propiedades urbanas, casas preferentemente, y solares en el medio rural ${ }^{49}$ o a la ocupación de algún cargo. ${ }^{50}$

En cambio, sí que tenemos constancia y más información sobre las solicitudes de cartas de naturaleza. ${ }^{51}$ Durante los siglos XVI y XVII las concesiones fueron bastante escasas, quizás porque el número de solicitudes tampoco fuese muy elevado. ${ }^{52}$ Dado que la gran mayoría se solicitaban para poder ejercer el comercio con las Indias y que buena parte de los mercaderes extranjeros radicados en el archipiélago lo realizaban sin ningún tipo de trabas aparentes, resulta lógico pensar que la reducida cuantía de concesiones es la consecuencia lógica de su inutilidad. Al menos hasta finales del siglo XVII, cuando la Casa de la Contratación consiguió limitar, tras varias décadas de lucha, las exportaciones canarias a América y un mayor control en el comercio con ese continente. A partir de entonces, se impuso la necesidad de contar con un cierto respaldo legal, la naturalización, ante las cortapisas de la institución lo que no significaba la renuncia a continuar desarrollando las actividades de manera ilícita o fraudulenta, como así lo ejercían la mayor parte de los comerciantes extranjeros. Ello propició que la mayor proporción de cartas de naturaleza para comerciar con América se concediesen entre 1728 y 1753, aunque su número continuó siendo irrisorio en comparación con las áreas peninsulares.

A mediados del siglo XVII la situación era notoriamente distinta a la vigente unas décadas atrás, merced a una serie de hechos y cambios que se venían gestando desde el comienzo de la centuria. Por un lado, una mayor tolerancia en lo que se refiere a la presencia de protestantes en los territorios de la monarquía hispánica; por otro lado, el debilitamiento de la Corona española frente a otras potencias europeas se traduce en el reconocimiento, cada vez mayor, de una serie de prerrogativas y concesiones favorables a los extranjeros, que obtendrán a través de los tratados internacionales y las cédulas reales concedidas por los monarcas españoles.

49. Casi todos los extranjeros avecindados en Gran Canaria adquirieron bienes raíces, preferentemente una vivienda que muchos ampliaban con terrenos en el medio rural. BRITO GONZÁLEZ, Alexis D.: Los extranjeros en las Canarias Orientales en el siglo XVII. Las Palmas de GC 2002, pp. 307-324.

50. En el ámbito civil, numerosos extranjeros ocuparon cargos en las islas a lo largo del Antiguo Régimen, desde las milicias hasta el regimiento. BRITo GONZÁLEZ, Alexis D.: «Extranjeros en el regimiento de Gran Canaria durante el siglo XVII». XIII Coloquio de Historia Canario-Americana (1998), Las Palmas de GC 2000, pp. 2335-2346; PAZ SANCHEZ, Manuel de (dir.): Flandes y Canarias: nuestros orígenes nórdicos. Sta. Cruz de Tenerife, Las Palmas de Gran Canaria, 2004; RosA OliverA, Leopoldo de la: «Francisco de Riberol y la colonia genovesa de Canarias». Anuario de Estudios Atlánticos n ${ }^{\circ} 18$ (1972), pp. 61-198. Sobre su participación en instituciones de carácter eclesiástico, BRITO GONZÁlEZ, Alexis D.: Los extranjeros en las Canarias Orientales... op. cit. pp. 362-363.

51. Brito GonZalez, Alexis D.: «Naturalizaciones de extranjeros en Canarias en el Antiguo Régimen». $X V$ Coloquio de Historia Canario-Americana (2002), Las Palmas de GC 2004, pp. 274-287.

52. Durante el siglo XVII, por ejemplo, se concedieron, al menos, tres cartas de naturaleza mientras que sabemos con certeza, a través de la documentación oficial o la recogida en los protocolos notariales, que cinco individuos más las solicitaron en ese período. 
Aunque se rubrican tratados con otros estados europeos desde inicios del Quinientos, realmente no será hasta las primeras décadas del Seiscientos en que adquieran importancia en lo que concierne a nuestro tema, al reflejar las condiciones jurídicas de los súbditos de dichos estados. Una consecuencia de la firma de dichos convenios internacionales la constituye la progresiva aparición de representantes de los distintos estados europeos en los territorios hispánicos con poderes para defender y representar los intereses de los súbditos de dichos estados. ${ }^{53}$ Para los países receptores, en esta caso España, los cónsules van a suponer una institución incómoda pues representa el fin de las situaciones arbitrarias y parciales contra los extranjeros, de ahí la reticencia a conceder las reales cédulas ratificando y aceptando su nombramiento y las constantes quejas de distintos organismos respecto a su intromisión en los asuntos que atañían a los foráneos. No obstante, a pesar de las dificultades iniciales y de los intentos de la Corona española por limitar su acción, ${ }^{54}$ lo cierto es que, desde mediados del siglo XVII, comienzan a instalarse en los principales puertos españoles tanto de la costa mediterránea como atlántica un número cada vez mayor de cónsules extranjeros. Los primeros tratados de comercio y navegación en los que se incluyen artículos para el establecimiento de cónsules son los ya citados con Dinamarca (1641) y Holanda (1648), aunque, como señala Pradells Nadal, la referencia esencial en las relaciones consulares de España durante el siglo XVII y gran parte del siglo XVIII serán los artículos 19 y 27 del tratado hispano-británico de 1667. En el artículo 19 se señalaba que «si se originase alguna controversia entre los comerciantes y los maestres de navio, o entre estos y los de la tripulación, se remitirá su composición al cónsul de la nación respectiva...». Más específico es el artículo 27 al apuntar que

«el cónsul que de aquí adelante residiere en los dominios del rey de España para el ausilio (sic) y protección de los súbditos del rey de la Gran Bretaña será nombrado por este mismo rey; y tendrá y ejercerá la misma potestad y autoridad para el cumplimiento de su empleo que haya tenido hasta aquí cualquier otro cónsul en los dominios del rey católico; y recíprocamente los cónsules de España residentes en Inglaterra gozarán de la misma autoridad que hasta aquí se ha permitido en dicho reino a los cónsules de cualquier otra nación $[\ldots] »$.

53. Aunque algunas de estas figuras tienen un origen cronológico anterior no será hasta este momento en que obtienen las características y singularidades propias de la etapa moderna, como por ejemplo los cónsules y jueces conservadores. Para el caso de los cónsules, véase PRADELls NADAL, Jesús: Diplomacia y comercio. La expansión consular española en el siglo XVIII. Alicante, 1992, pp. 35-43.

54. Un medio para constreñir sus acciones consistía en retrasar la concesión de la real cédula de nombramiento, lo que conllevaba que muchos cónsules ejercieran sin ella. Por ese motivo, a pesar de una orden enviada en 1661 en la que el Consejo de Estado reiteró las órdenes de que los cónsules no pudiesen ejercer sin la real aprobación, unos años más tarde volvió a decidir "[...] que debe VM servirse de mandar se reitere la orden que se envio el año de 61 a fin de que se recojan los titulos de los consules que se hallare ejercen sin la Real aprobacion despachada por estado [...] y que de ninguna suerte admitan ni puedan admitir al uso del consulado a ninguno que con el nombramiento de su Rey o republica no presentase tal despacho de VM [...]». (A)rchivo (G)eneral de (S)imancas Sección Estado Leg. 4191 s.f. (1666/Junio/8). 
En esta materia, Canarias no va a constituir una excepción. A pesar de contar con una nutrida colonia de foráneos en las islas desde los momentos iniciales de la colonización, la institución consular no hará acto de presencia hasta mediados del siglo XVII cuando en otros puertos peninsulares se hallaba plenamente instalada desde el siglo anterior, e incluso con anterioridad. Una de las causas de este tardío establecimiento lo podemos encontrar en la carencia de una tradición de la misma en el archipiélago por su incorporación a la Corona castellana a finales del siglo $\mathrm{XV}$; al mismo tiempo, la escasa conflictividad en torno a la colonia de los europeos puede suponer otro factor que no se debe descartar pues habría impedido o coartado la reclamación de algún estado para contar con representación consular hasta que la necesidad se convirtiese en algo imperativo.

Los primeros cónsules que se instalan en las islas serán los holandeses en la década de 1650 pero no será hasta la de 1660 y 1670 cuando lo hagan los ingleses y franceses, caracterizándose estos primeros instantes por una falta de continuidad en los nombramientos y una escasez documental en torno a su actuación. De ahí que no será realmente hasta la transición al siglo XVIII en que la institución consular se asiente con firmeza y de manera permanente. ${ }^{55}$ En 1698, Hamburgo solicita la facultad de poder nombrar cónsul en la isla de Tenerife, petición aprobada al año siguiente, y los genoveses contaron igualmente con un consulado en las islas pero ya en el siglo XVIII. ${ }^{56}$

Si bien es cierto que algunos de estos individuos chocaron con las autoridades, en especial las eclesiásticas como sucedió con el cónsul inglés Edmund Smith a fines del Seiscientos, las relaciones de los mismos con la sociedad canaria se pueden tachar de normales y regulares, integrándose muchos de ellos en los estratos sociales superiores, lo que nos indica que, a pesar de representar los intereses de sus respectivas naciones, no suponían una fuente de conflictos para la administración regia. El caso más paradigmático sea, quizás, el de la familia Porlier. Etienne (o Esteban) Porlier llegó a las islas en 1706, el mismo año en que contrajo matrimonio en Tenerife. Nombrado cónsul en 1713 ejerció el cargo hasta 1739, año de su fallecimiento; su hijo Juan Antonio ocupó el cargo hasta 1749 aunque sin el exequátur correspondiente. ${ }^{57}$

55. Para más información sobre las primeras décadas, BRITO GONZÁLEZ, Alexis D.: «Cónsules en Canarias en el siglo XVII y transición al siglo XVIII». XII Coloquio de Historia Canario-Americana (1996), Las Palmas de GC 1999, Tomo II pp. 143-164; GALINDO BRITO, Antonio: «Los cónsules ingleses en Canarias en el siglo XVII». XVI Coloquio de Historia Canario-Americana (2004), Las Palmas de GC 2006, pp. 473-480; SANTANA PÉREZ, Germán: «Los inicios del consulado de Francia en las islas Canarias: actuación y funciones en un período de conflictos bélicos». Arquipélago-Historia, $2^{\mathrm{a}}$ serie (2001) pp. 73-87

56. El cónsul hamburgués nombrado fue Hermann Enrique Wahn aunque parece que el consulado no tuvo demasiada continuidad en el siglo XVIII. A.G.S. Estado Leg. 4191 4192, s.f. Sobre el consulado genovés, vid. PELLEGRINI, Sandro: Il consolado genoveses alle Canarie (1710-1805). Génova 1997.

57. OzAnAm, Didier: «El consulado francés en Canarias y la familia Porlier». XIV Coloquio de Historia Canario-Americana (2000), Las Palmas de GC 2002, p. 2173-2185. Sobre esta familia véase también Chanel-Tisseau Des Escotais, Josette: Les Iles Canaries et les colonies espagnoles d'Amérique dans la correspondance inédite des consuls de France à Ténérife, 1670-1755. Tesis doctoral inédita, 1985; «La problemática del comercio francés en Canarias a principios del siglo XVIII a través de la correspon- 
La otra figura encargada de defender a los extranjeros en los territorios hispánicos estará formada por los jueces conservadores. Esta institución parece que surgió por primera vez en el tratado de 1607 con las ciudades hanseáticas; tal y como apuntamos en el apartado anterior, este privilegio se amplió en 1645 cuando Felipe IV concedió a los ingleses la posibilidad de contar con uno en varias ciudades andaluzas. ${ }^{58}$

El primer juez conservador de los ingleses fue el capitán general Gabriel Lasso de la Vega, conde de Puertollano, en $1669,{ }^{59}$ merced que fue posteriormente ampliada a la nación holandesa, que logró contar con su propio juez a partir de 1691, y de los cuales también lo sería el capitán general, siendo el primero el conde de Eril. ${ }^{60}$ Esta peculiaridad de los jueces conservadores en Canarias fue reconocida en el siglo XVIII al incluirse un artículo separado en el Tratado de Utrecht por el que se concedía un juez conservador a la colonia inglesa del archipiélago, aunque con ciertas restricciones pues únicamente entendería en cuestiones de materia mercantil. ${ }^{61}$

En Canarias, dicha institución detenta una peculiaridad propia; a diferencia de algunas zonas de la Península, en el archipiélago este cargo va a estar ostentado por los capitanes generales, en los cuales la colonia pertinente deposita su entera confianza para defenderles con firmeza ante el resto de los organismos insulares (Audiencia, Cabildos) así como de la Inquisición. Esto suponía de por sí una paradoja ya que el capitán general constituía el máximo representante de la Corona y también de una nación extranjera, lo que suponía que en caso de conflicto entre ambas, cosa no harto difícil, debería inhibirse de representar a una de las partes, situación que al mismo

dencia consular francesa». V Coloquio de Historia Canario-Americana (1982), Las Palmas de GC 1985, Vol. II pp. 479-500; «El papel de las mujeres en la promoción social de la familia Porlier». XVI Coloquio de Historia Canario-Americana (2004), Las Palmas de GC 2006, pp. 756-762.

58. Las ciudades andaluzas eran Sevilla, Málaga, Cádiz y Sanlúcar de Barrameda. Citado en ALvAREZVALDÉS, Manuel: op. cit. pp. 402-404.

59. A.H.P.L.P. Sección Audiencia Libro 3 (Reales Cédulas) fol. 132 rto.-134 rto. Manuel Pérez Rodríguez señala en su obra Los extranjeros en Canarias pp. 241 que el primer juez conservador fue el capitán general Pedro Carrillo sin ofrecer ninguna referencia de su nombramiento; la única concordancia viene dada en que era el capitán general cuando Felipe IV promulgó la cédula de 1645 concediendo esta merced a los ingleses. Sin embargo, no hay que olvidar que sólo se dio para determinados puertos andaluces y no para la totalidad del territorio español; esta situación sólo sería extendida en el artículo 9 del tratado de 1667.

60. Nombramiento efectuado por Real Cédula de 9 de Agosto de 1691. A.G.S. Sección Estado Leg. 4192 s.f. También en A.H.P.L.P. Sección Audiencia Libro 4 (Reales Cédulas) fol. 63 rto.

61. «[...] consiente su real Majestad católica que de hoy en adelante sea lícito a los súbditos de la Gran Bretaña que con motivo del comercio residen en las islas de Canaria, nombrar alguno de los súbditos españoles para que tenga alli el empleo de juez conservador, y conozca en primera instancia de todas las causas mercantiles de ingleses; y promete su real Majestad que concederá al tal juez conservador, asi nombrado, las comisiones juntamente con la autoridad misma y todos los privilejios de que los jueces conservadores han gozado hasta aqui en Andalucía, o también si los súbditos ingleses desearen tener alli mismo muchos de estos jueces, o mudar cada trienio a los nombrados les será permitido y se les concederá. Consiente también el rey católico que las apelaciones de las sentencias del dicho juez conservador se lleven al tribunal del consejo de guerra de Madrid, y no a otra parte». En CANTILLO, Alejandro del: op. cit. pp. 152. 
tiempo podía levantar suspicacias sobre qué intereses realmente defendía. En el siglo XVII este hecho fue obviado y no se le dio, o quiso dar, relevancia y, en efecto, varios capitanes generales fueron jueces conservadores. Sin embargo, con la llegada al trono de la dinastía borbónica se transforma la coyuntura; cuando, en 1714, D. Ventura de Landaeta, el capitán general de ese momento, solicitó la ratificación del nombramiento de juez conservador hecha en su persona por la colonia inglesa, el Consejo de Estado dictaminaba que

«[...] se reconoce inconveniente considerable en que lo sea D. Ventura de Landaeta porque hallandose capitan general es quien principalmente representa a VM y debe celar en la observancia de las leyes y en que los extranjeros no excedan de lo que por capitulos de paces les estuviere concedido [...] es de parecer esta Junta que VM se sirva mandar responder a D. Ventura de Landaeta que por no poder concurrir en su persona esta judicatura por su empleo de capitan general se le devuelva la nominacion hecha por los de la nacion inglesa para que nombre otro $[\ldots]\rangle^{62}$

y no se le llegó a dar el visto bueno para gozar de tal nombramiento. Este hecho junto a las restricciones generales a los nombramientos en las décadas de 1710 y 1720 , como vimos más atrás, puede considerarse como el inicio de la decadencia de esta institución en el archipiélago, pues la documentación sobre sus nombramientos y conflictos prácticamente desaparecen.

Uno de los hechos más impactantes que sucedieron en el Setecientos insular respecto a los extranjeros fue la expulsión decretada por Felipe V en 1729 de los comerciantes protestantes. Hecho inusual pues hasta la fecha no se había producido ninguna situación semejante a aquella; si bien con motivo de los conflictos bélicos, los miembros de distintas nacionalidades habían salido de las islas, ésta nunca se había ordenado desde la Corte de manera tan directa. En 1726, Felipe V había solicitado al capitán general, que lo era entonces el Marqués de Valhermoso, un informe sobre los daños que originaban al comercio de las islas la introducción y avecindamiento de extranjeros hugonotes (entiéndase protestantes) según había representado D. Alonso de Fonseca, diputado de la isla de Tenerife. A pesar de que, por carta de 26 de Mayo de 1727, el capitán general informaba de únicamente la presencia de tres hugonotes avecindados como cristianos reformados, el monarca

«haviendose visto en mi Consexo de las Indias [...] con lo que en inttelixenzia de todo expuso mi fiscal y consultandome sobre ello como quiera que bea reconosido ser sierto el comerzio que tienen los estrangeros en las yndias desde esas Yslas valiendose de el permiso de ellas [...] e resuelto ordenar y mandar (como lo hago) por despacho de este dias al mencionado Marques de Valhermoso mi Governador y Capitan General de esas Islas que desde luego disponga salgan de ella los extranjeros hereges que hubiere dandoles termino competente para ello y para que en adelante sesen estos daños hordenaros a vos que arreglandoos a los capitulado por ellas a quienes esta consedido el permizo de poder

62. Minuta de consulta de la Junta de Dependencias de la Nación Francesa sobre el nombramiento del juez conservador que solicitaban los ingleses en 30 de Septiembre de 1714. A.H.N. Sección Estado Leg. 619 (Caja 2). 
comerciar a los puertos de las indias solo los vezinos de esa Isla la de Canaria y la Palma seceis sobre este comerzio no permitiendo a los extrangeros lo tengan en las Indias por si ni por ynterposittas personas $[\ldots]\rangle^{63}$

Por un bando con fecha de 27 de Mayo de ese mismo año, el Marqués de Valhermoso otorgaba un plazo de dos meses a los protestantes para salir de las islas con pérdida de los bienes en caso de incumplimiento y pena de quinientos ducados para aquellos que los encubran. ${ }^{64}$ Como en muchas otras ocasiones no llegó a ejecutarse, quizás por la presión diplomática de Gran Bretaña; los protestantes siguieron acudiendo a los puertos insulares a ejercitar las actividades comerciales. ${ }^{65}$

No fueron los únicos intentos por expulsar a extranjeros en este período. Al declararse la guerra con Portugal en 1762 se decretó la expulsión de los portugueses, a excepción de los que ejerciesen oficios mecánicos; ${ }^{66}$ lo mismo sucederá en 1797 con los súbditos ingleses. ${ }^{67}$

La presión sobre los extranjeros fue una de las constantes del siglo XVIII por parte de la Corona española. En su intento de controlar sus actividades, sobre todo en lo que concernía al ámbito americano, actuó con cierta dureza en comparación con etapas pasadas. Un colectivo que conoció dichas dificultades fue el de los malteses. Acusados de comerciar con productos de baja calidad, su número fue incrementándose a lo largo del Setecientos, obligando a actuar a los monarcas españoles. Una orden de la Junta de Comercio y Moneda, con fecha de 11 de Enero de 1771, mandaba que

«todos los Malteses que se hallasen con casa y tienda fixas en estos Reynos, y quisiesen continuar en ellos su comercio por menor, habían de renunciar en el tiempo de ocho días su propio fuero y domicilio, avecindándose como vasallos de S.M., con incorporación a su respectivo gremio y sujeción a las leyes Reales, estatutos municipales y demás cargas concejiles; otorgando la correspondiente escritura de renuncia de fuero $[\ldots]\rangle^{68}$

en caso contrario no podían dedicarse al comercio por menor sino al mayor y en grueso. En la ciudad de Las Palmas al menos hemos contabilizado a un grupo de seis

63. Real Cédula de 14 de Febrero de 1729 dirigida al capitán D. Bartolomé de Casabuena y Mesa, juez superintendente del comercio de Indias en Canarias. (A)rchivo (H)istórico (M)unicipal de (L)a (L)aguna R-XVIII exped. 28.

64. A.H.N. Sección Estado Leg. 550.

65. El cónsul inglés envió cartas a Inglaterra informando sobre este tema, lo que se puso en conocimiento del embajador inglés en España. Ruiz Alvarez, Antonio y SERrA RAFOLS, Elías: «El marqués de Valhermoso y los comerciantes ingleses. 1729». Revista de Historia Canaria (1961), N 133-134, pp. 146-150.

66. Se otorgaba un plazo de quince días para cumplir la orden. En GUERRA Y PEÑA, Lope Antonio de la: Memorias (Tenerife en la segunda mitad del siglo XVIII). Las Palmas, 1951, Cuaderno I pp. 49-50.

67. Cioranescu, Alejandro: Historia de Santa Cruz de Tenerife. Sta. Cruz de Tenerife, 1977 Vol. I pp. 382 nota 90 .

68. Novísima Recopilación de las Leyes de España. Madrid, 1805, Libro VI Título XI Ley III, nota 1. 
que renunciaron, aunque pudieron producirse algunas más $;{ }^{69}$ de los residentes en la ciudad de Santa Cruz de Tenerife lo hicieron cuatro. ${ }^{70}$

Poco después, la misma Junta ordenó el 18 de Mayo de 1774 que los malteses que quisiesen avecindarse debían afianzar su permanencia, al estar prohibido que los vasallos saliesen del país sin licencia del rey, aunque poco después, por orden de 17 de Octubre de ese mismo año, se les permitió dar fianza entre ellos siempre que, al menos, fuesen tres y ya establecidos con tienda y comercio. ${ }^{71}$ Ello no afectó en gran medida a la colonia maltesa en las islas pues continuaron con sus actividades mercantiles y asentándose en los puertos canarios, como lo demuestra el hecho de que formaban uno de los colectivos foráneos más numerosos a finales del siglo XVIII. ${ }^{72}$

Indudablemente, los malteses no fueron los únicos. Cómo señalamos en el apartado general, Carlos III ordenó en 1764 la elaboración de una serie de matrículas que, con carácter anual, recogiesen a aquellos individuos naturales de otro país junto a una serie de datos, como edad, profesión, estado civil, religión que profesa, tiempo de residencia, etc. Por diversos motivos, no se produjo una persistencia en la confección de dichas listas; en Canarias, incluso se puede señalar que fueron testimoniales pues únicamente se realizaron durante los años 1765 y 1766 . La fragmentación del territorio, las dificultades a la hora de recabar los datos, la connivencia de las autoridades con los comerciantes extranjeros e, incluso, la desidia de aquellas son factores que nos ayudan a explicar la negligencia en el cumplimiento de las órdenes reales.

La Revolución Francesa se constituyó en un revulsivo a la hora de dictar nuevas normas sobre los extranjeros a finales del Antiguo Régimen. El temor a la expansión de las ideas revolucionarias propició la toma de medidas de control, sobre todo de propaganda y escritos subversivos así como de información proveniente de Francia. Sin embargo, la detención de Luis XVI y la radicalización de la revolución produjeron importantes cambios. El 20 de Julio de 1791 Carlos IV promulgaba una Real Cédula en la que se ordena hacer las matriculas de los extranjeros residentes en el reino. ${ }^{73}$ La Real

69. Brito GonzÁlez, Alexis D.: «La colonia maltesa en Las Palmas en el Antiguo Régimen». I Coloquio Internacional «Los extranjeros en la España moderna» (2002), Málaga 2003, pp. 219-240.

70. Cioranescu, Alejandro: Historia de ... Vol. I pp. 379 nota 59.

71. Novísima Recopilación de las ... Libro VI Título XI Ley III, notas 2 y 3.

72. Por ejemplo, según los datos recogidos en las matrículas de 1791, los malteses suponían el 14’7\% de los extranjeros en la ciudad de Las Palmas, por encima de cualquier otra nacionalidad entre los avecindados, y el 16'2\% en la isla de Tenerife. BRITO GonZalez, Alexis D.: «Matrículas de extranjeros en Canarias durante la segunda mitad del siglo XVIII». Anuario de Estudios Atlánticos, Las Palmas-Madrid, $\mathrm{n}^{\circ} 45$ (1999), pp. 219-260.

73. Además, debían declarar si querían permanecer como avecindados y súbditos del monarca español; en caso de querer avecindarse, debían ser católicos y hacer un juramento de fidelidad. Los transeúntes no podían ejercer las artes liberales ni oficios mecánicos sin avecindarse, es decir, no podían ser mercaderes de vara, vendedores por menor, sastres, modistas, peluqueros, zapateros, médicos, cirujanos, arquitectos, etc. ni criados; a los cuales se les daba un período de quince días para salir de la Corte y dos meses de los reinos o renunciar al fuero de extranjería, avecindarse y realizar el juramento. Recogida en la Novísima Recopilación ... Libro VI Título XI Ley VIII. 
Cédula iba acompañada de una Instrucción con fecha de 21 de Julio en la que se explicaba la manera correcta de aplicar la cédula, cómo elaborar las matrículas y las excepciones a las mismas; por ejemplo, en el artículo 9 se establecía la formación de listas separadas para maestros y oficiales que no profesasen la religión católica y que trabajasen en fábricas de cualquier tipo de manufacturas. Poco después, una Real Cédula de 29 de Noviembre de ese año ordenaba la rectificación anual de las matrículas.

Sin embargo, la orden que más atañe a la situación jurídica lo supuso la Real Provisión de 4 de Marzo de 1793 que ordenaba la expulsión de los franceses no domiciliados del territorio español. Además, incluía una Instrucción con la manera de ejecutar el extrañamiento ordenado.

En Canarias, parece que únicamente se han conservado los expedientes de los franceses que residían en la isla de Tenerife. ${ }^{74} \mathrm{~A}$ raíz de la orden se realizaron tres listas, la primera con fecha de 28 de Septiembre de ese mismo año en el que se recogen hasta 22 individuos de esa nacionalidad, de los que serían expulsados ocho, quedando el resto como avecindados. Los expedientes contra el cónsul y el vicecónsul fueron realizados por el Comandante General, a diferencia del resto de sus connacionales que lo fueron por la justicia ordinaria.

Además, la Real Cédula de 24 de Diciembre de 1793 ordenaba que se enviasen a las islas seiscientos prisioneros franceses que estaban en Barcelona, los cuales fueron instalados en el Hospital y Lazareto situado en las cercanías de Santa Cruz de Tenerife. Pocos años más tarde, en 1798 se decreta que pasen a Canarias un grupo importante de emigrados franceses. Los cabildos de Gran Canaria y Tenerife encargaron al Diputado general de las islas ante la Corte realizase gestiones para impedir dicha acción, la cual finalmente no se produjo, tal vez debido principalmente a las dificultades para encontrar pasaje a los refugiados desde el puerto de La Coruña más que a un éxito propio de los representantes insulares.

\section{CONCLUSIONES}

En las páginas precedentes hemos desglosado las circunstancias jurídicas que envolvieron la presencia de los europeos en Canarias durante el Antiguo Régimen. Circunstancias que normalmente se hallaban adaptadas a las normas generales promulgadas por la Corona para todos los territorios bajo su dominio. No obstante, en ocasiones se produjeron casos que atañían exclusivamente al archipiélago, como fue el caso del artículo separado del Tratado de Utrecht por el que se permitía a los ingleses nombrar un juez conservador que entendiese en primera instancia de todas las causas mercantiles de los comerciantes de dicha nación.

Como señalamos al comienzo, en el Antiguo Régimen no existe un corpus legislativo especial centrado en los foráneos. La legislación va surgiendo según las necesidades, los conflictos internacionales con otras naciones y las demandas, tanto por parte

74. Guimera Ravina, $\mathrm{M}^{\mathrm{a}}$ del Carmen: «Tenerife y la guerra contra la Revolución Francesa». Anuario de Estudios Atlánticos, Las Palmas-Madrid, nº 21 (1975), pp. 131-176. 
de los susodichos como por parte de los súbditos del rey, formando un conglomerado de disposiciones, decretos, provisiones y demás autos que, a comienzos del siglo XIX, hace necesario su integración en la recopilación realizada bajo el reinado de Carlos IV. Sin embargo, un punto común a la mayor parte de las normas jurídicas que se dictan en este período es su referencia al ejercicio del comercio, por lo general de carácter restrictivo, y al tema de la naturalización y avecindamiento de estos individuos. Y en el caso de los europeos que residen en Canarias esta constituye la tónica más habitual, ya que casi todas las disposiciones sobre el comercio lo hacen para recordar las prohibiciones de sus actividades con Indias.

Asimismo, se percibe un cierto relajamiento en las aplicaciones de dichas normas legales. La lejanía respecto a la Corte, los estrechos vínculos de los capitanes generales, gobernadores y cualquier institución, incluso las eclesiásticas, con los extranjeros y la necesidad imperiosa del archipiélago de contar con estos individuos en sus relaciones comerciales propiciaron que algunas normas se implantasen de manera más suave, o incluso fuesen obviadas. Sólo aquellos preceptos que requiriesen una aprobación desde la Corte, como por ejemplo la concesión de cartas de naturaleza, se cumplían de manera estricta. Las reiteradas disposiciones prohibiendo a los extranjeros comerciar con Indias durante la segunda mitad del siglo XVI y la mayor parte del siglo XVII no son sino una muestra del sistemático incumplimiento de las mismas, lo cual no podía desarrollarse sin la aquiescencia de los poderes civiles de las islas.

Ello no era óbice para que, en casos muy puntuales, las autoridades se comportasen con cierta dureza, como sucedió en el intento de expulsión de los comerciantes ingleses en 1729, aunque luego no fuese llevado a cabo.

En síntesis, podemos señalar que, si bien la situación jurídica de los extranjeros que residieron en Canarias en la etapa moderna no se diferencia de manera esencial de la del resto de los europeos que residieron en los territorios hispánicos, pues existe un sustrato legal común e inherente a todos ellos, sí que existen ciertas disposiciones específicas que se tradujeron en algunos cambios concretos, centrados principalmente en el ámbito de las actividades comerciales. 